\title{
DELITO Y ESPACIO EN CIUDADES INTERMEDIAS: AFINANDO UN MODELO DE ANÁLISIS TERRITORIAL EN GERONA, TARRAGONA Y LÉRIDA*
}

\author{
Pedro Fraile \\ Quim Bonastra \\ Departamento de Geografía y Sociología. Universidad de Lleida \\ PEDROFRL@telefonica.net / quim.bonastra@geosoc.udl.cat
}

\section{RESUMEN}

En estas páginas se estudia la lógica locacional de ciertos delitos en tres ciudades intermedias de Cataluña: Gerona, Lérida y Tarragona; con el objetivo de validar y afinar modelos formulados con anterioridad. Se analiza el emplazamiento de contravenciones con una lógica estructural, es decir, con una tendencia a la estabilidad territorial vinculada a funciones y rasgos urbanos. El análisis se ha centrado en los hurtos y en los robos con violencia o intimidación, cotejando estos últimos con las lesiones y los delitos contra el orden público para esclarecer sus dinámicas internas.

El trabajo ha permitido definir áreas específicas que atraen y estabilizan estas contravenciones y abre la reflexión sobre los rasgos del espacio público que pueden propiciar la sensación de seguridad en la ciudadanía.

Palabras clave: Delincuencia, seguridad, lógica espacial, conflictividad urbana.

\section{ABSTRACT}

These pages investigate the location logic of certain crimes in three intermediate cities of Catalonia: Gerona, Lérida and Tarragona, with the aim of validating and fine-tuning previously-

Fecha de recepción: marzo 2013.

Fecha de aceptación: febrero 2014

* Este artículo es fruto de dos proyectos de investigación financiados por el Ministerio de Ciencia e Innovación: Espacio urbano, delincuencia y percepción ciudadana: el caso de Lleida (SEJ2005-01879GEOG); Delito, conflicto, seguridad y paisaje urbano en ciudades intermedias de Cataluña: los casos de Gerona, Tarragona y Lleida (CSO2008-02746GEOG). 
formulated models. It analyzes the location of crimes that show a structural logic, that is, that have a tendency towards territorial stability linked to urban features and functions. The analysis has focussed on robberies or thefts with violence and intimidation. These have then been compared and contrasted with assaults and crimes against public order in order to clarify their internal dynamics.

The research has allowed us to identify and define specific areas that attract and foment these sorts of violations and to invite further thinking about features of public space that can be conducive to a sense of security amongst urban citizens.

Key words: Crime, security, spatial logic, urban conflictivity.

\section{DELITO Y ESPACIO}

La relación entre la delincuencia, su localización y la sensación de seguridad, se ha estudiado ampliamente desde una perspectiva geográfica, dando lugar a una larga tradición que ha sido minuciosamente analizada (Hernando, 2006a, 2011; Fraile, Bonastra, 2011) y también ha generado multitud de trabajos empíricos, algunos de ellos acometidos en España, como los de Stangeland (1995, 2004), Hernando (2007a, 2007b) o Fraile y Bonastra (2010, 2011, 2012), aunque en ocasiones desde perspectivas bien diferentes. Esta reflexión, en lo sustancial, obedece a dos grandes enfoques (Bottoms, 2012) que muchos consideran, en cierto sentido, complementarios. Por un lado estaría la teoría de la desorganización social (social disorganization) (Shaw y McKay, 1942) y, por otro, la de la actividad rutinaria (routine activity) (Cohen y Felson, 1979). Según la primera, la desestructuración social de un área es la variable significativa que explica la comisión de delitos. Para la segunda, éstos están sujetos a la convergencia en el espacio y el tiempo de perpetradores motivados, víctimas posibles y la ausencia de vigilancia. Los primeros estudios se han basado, sobre todo, en los índices socioeconómicos de los lugares donde residen los delincuentes, mientras que los segundos han puesto el acento en las funciones predominantes en el espacio urbano, que sirven como indicador de las relaciones de la ciudadanía entre sí y con su entorno.

Puesto que desde la preocupación que anima estas páginas es importante el espacio público, y el uso que de él se hace, conviene también señalar nuestra posición al respecto. Partimos de la idea de que los espacios que usamos en nuestra vida diaria influyen en la configuración de las interacciones sociales que se dan en ellos y que, recíprocamente, los primeros se ven transformados por las segundas ${ }^{1}$. De acuerdo con Dear y Wolch, el espacio es un producto social lleno de intencionalidad y no puede separarse de la práctica social como si se tratara de una estructura independiente (Dear y Wolch, 1989: 6). De este modo, si trasladamos estos criterios a la relación entre delito y espacio urbano, cabría afirmar, por un lado, que la comisión de algunos delitos deja una impronta allá donde se producen y, a su vez, ciertos lugares, por sus rasgos morfológicos y funcionales, pueden propiciar que éstos tengan lugar. En otras palabras, el espacio urbano y sus características (entendiendo que nos referimos tanto a las características físicas, las formas del medio construido, como a sus niveles de actividad, flujos de personas, funciones urbanas etc.) debe ser entendido como una

1 Dos obras clásicas que avanzan en este sentido son las de Gregroy y Urry: 1985 y la de Wolch y Dear: 1989. 
dimensión activa en la perpretación de delitos (Hillier y Sahbaz, 2005: 454). Esta imbricación socio-espacial puede tener como corolario una mala imagen de estos lugares, limitando el alcance de las relaciones sociales en ellos y provocando, progresivamente, su deterioro. Es por eso que, para evitar el menoscabo del escenario por excelencia de la vida social, es de la mayor importancia ahondar en el estudio de los vínculos existentes entre el espacio público y el delito y diseñar un modelo analítico que permita entender su lógica locacional, lo que podría ser una herramienta de la mayor utilidad para el diseño de estrategias preventivas e, igualmente, ayudaría en el diseño de la ciudad, de las políticas urbanísticas o de algunos planes concretos de intervención.

Antes de adentrarnos en la exposición de los objetivos concretos que perseguimos, así como de la metodología y el instrumental que hemos utilizado, parece necesario explicar en qué principios se basa esta investigación, porque ello ayudará a entender la manera de proceder pero, puesto que ya se ha hecho en otros trabajos, nos permitiremos ser muy escuetos.

En primer lugar, partimos de la idea de que las profundas transformaciones sociales y económicas, que desde finales del pasado siglo han cambiado profundamente el mundo en el que vivimos (Castells, 1995; Beck, 2006; Bauman, 2003a; Giddens, 1999), tienen una incidencia notable en algunas categorías delictivas. Hoy, prácticamente todas las transgresiones de la norma legal, desde el menudeo en el tráfico de drogas a ciertos hurtos, aparentemente de poca importancia, o a robos de mayor entidad, tienen que ver, de diferentes maneras, con redes que se extienden, y están trabadas a nivel internacional (Recasens, 2003: 369; Maillard, 2002), lo que les da un carácter relativamente distinto del que tenían ciertos delitos en el ochocientos o a mediados del siglo pasado. Estamos, por tanto, frente a uno de esos fenómenos que se han calificado con el neologismo de glocal, subrayando la idea de que se manifiesta en el ámbito local pero está imbricado en dinámicas globales. Este hecho es de una importancia capital para entender la lógica locacional de determinados fenómenos.

Por otro lado, puesto que uno de los acicates importantes para emprender investigaciones de este tipo es comprender la percepción de seguridad de la población, con qué lugares se vinculan determinados temores y qué fenómenos los generan, hemos de señalar, una vez más, que la delincuencia que es posible cartografiar, y que dista bastante de la realidad, sólo explica una parte de esas sensaciones colectivas. Por tanto, lo que se exponga en estas páginas, centrado en las contravenciones registradas, se deberá complementar con los datos recogidos sobre percepción, más subjetivos, que abordaremos en otra publicación.

Tal como hemos explicado en otras ocasiones, la sensación de seguridad, a menudo, está vinculada a determinados conflictos, a usos diferenciados y enfrentados del espacio público, a la difusión de algunos estereotipos o a otros factores de este tipo difícilmente objetivables y cuantificables. En resumen, la información sistematizada y tratada que aquí presentamos, sobre delitos e intervenciones policiales en ciudades intermedias, sólo explica una parte de la sensación de seguridad de la ciudadanía, pero puede ser muy útil para ver con qué morfologías y funciones urbanas se relacionan ciertos hechos.

Por último, en esta declaración de principios, convendría señalar nuestro distanciamiento de lo que ha dado en llamarse lógica actuarial (Hebberecht, 2003: 356; Reichman, 1986; Domínguez, Rodríguez, 2003: 331; Fraile, Bonastra, 2011: 127-130), es decir, aquel discurso que, partiendo de que el delito es parte consustancial del sistema social y económico, lo cual sería coherente con la concepción de la sociedad del riesgo tal como la han planteado Beck y 
otros, asume que la recogida de datos al respecto y su sistematización tienen por finalidad su gestión, dirigida a paliar sus efectos, soslayando el diseño de aquellas estrategias que cabría dirigir al núcleo del problema y, por tanto, su objetivo es colocar la eventualidad calculada de la contravención dentro de unos márgenes asumibles socialmente.

Desde nuestro punto de vista, tal enfoque plantea serios problemas. Por un lado porque limita las posibilidades de actuación desde los poderes públicos, que podrían ponerse en marcha a partir de una reflexión compleja sobre la delincuencia, la conflictividad y la percepción de seguridad. Por otro, porque empobrece la propia reflexión científica, al soslayar aspectos relevantes que intervienen en la conformación de estos fenómenos, así como en su lógica locacional. Relacionar esta problemática con morfologías y funciones urbanas, usos del espacio público y cualidades del mismo, políticas municipales y de intervención social, va más allá de la mera localización de los hechos y ese es el objetivo que perseguimos en nuestro trabajo, de ahí el interés por afinar modelos explicativos que sean aplicables en ámbitos definidos con precisión y que puedan contribuir al diseño de políticas de carácter general.

Finalmente, aunque quizás sea un telón de fondo relativamente difuso, parece importante señalar una vez más que, tanto el delito como el conflicto, son, en cierto modo, construcciones sociales en las que tienen un peso considerable determinados imaginarios colectivos, así como algunos discursos asumidos socialmente como verdades ${ }^{2}$, que condicionan la percepción de la vida cotidiana y, en particular, el tipo de fenómenos que aquí nos ocupan.

\section{EL OBJETO DE ESTUDIO}

Este trabajo, en el que validaremos y afinaremos un modelo explicativo que ya ha sido expuesto con anterioridad, obedece a una investigación de largo recorrido que comenzó en la ciudad de Lérida y que, posteriormente, se ha extendido, además, a Gerona y Tarragona. En esta segunda fase nos marcamos como objetivo prioritario comprobar si las afirmaciones que se habían hecho para Lérida, y que se pretendían aplicables a otras urbes de rango y tamaño similares, se cumplían también en las otras capitales provinciales que considerábamos de características equiparables a la primera.

Nuestro estudio se centra, por tanto, en ciudades intermedias de Cataluña pero entendemos que, en lo sustancial, las conclusiones son extensibles a esa categoría urbana tanto en España como en una buena parte de Europa aunque, lógicamente, hacen falta más análisis de este tipo para ir corroborando las hipótesis que aquí se dan por parcialmente demostradas. Obviamente, no se nos escapa que ciertas ciudades intermedias, con un carácter muy específico, y por tanto con unas funciones urbanas muy marcadas, tendrán unos rasgos propios y una dinámica relativamente diferente, pero tal precisión está pendiente de trabajos empíricos que están por realizarse.

La primera investigación, centrada en Lérida, abarcó el periodo 2005-2007 y la siguiente, ampliada a Gerona y Tarragona, de 2008 a 2011, dedicando este último año al tratamiento de la información y el siguiente a la reflexión y a la presentación de resultados, tanto a las instituciones implicadas como a la comunidad científica. Entre ambas se extienden por un

2 Al hablar de discursos que funcionan como verdades lo hacemos en el sentido que le da Foucault, por ejemplo en Foucault, 1981:148. 
periodo de seis años y están diseñadas siguiendo el mismo patrón, precisamente con el objetivo de obtener series históricas significativas, especialmente en el caso de Lérida, así como avanzar hacia la construcción de un modelo tan generalizable como sea posible.

Hemos basado el trabajo en tres pilares, que aquí nos limitamos a describir someramente. Por un lado hemos sistematizado y cartografiado las denuncias e intervenciones policiales provenientes de las bases de datos de los Mossos d'Esquadra (Policía Autonómica de Cataluña). Por otro, hemos realizado tres encuestas de victimización, siguiendo el modelo de la ICVS (International Crime and Victimation Survey) con ligeras modificaciones, sobre sendas muestras de 2.500 personas en Gerona y Lérida y de 1.500 en Tarragona, disminución que obedeció a razones presupuestarias y, finalmente, hemos entrevistado a las principales asociaciones cívicas de las tres ciudades ${ }^{3}$.

Obviamente, el presente artículo obedece a una parte de tal investigación y, por consiguiente, el material empírico sistematizado que aquí no se recoge dará lugar a otras publicaciones de carácter científico, que complementarán los resultados que ahora presentamos. En estas páginas, por tanto, nos ocuparemos del tratamiento de las bases de datos policiales, las cartografiaremos y extraeremos conclusiones de la lógica locacional de ciertas contravenciones.

En general, hemos trabajado sobre los delitos ${ }^{4}$ que consideramos con mayor incidencia en la percepción de seguridad de la ciudadanía, fundamentalmente porque tienen lugar en el espacio público o repercusiones notorias en su entorno o en los medios de comunicación, pero aquí hemos limitado nuestro análisis a los que se pueden considerar con una lógica locacional de carácter estructural (Fraile, Bonastra, 2011), es decir, que se trata de contravenciones que tienden a buscar un cierto tipo de lugares y de funciones urbanas, aproximándose, por ejemplo, a las áreas que concentran las actividades comerciales o de ocio, lo que les confiere una cierta estabilidad territorial. En estas páginas centraremos

3 Se han entrevistado en cada ciudad a una veintena de asociaciones de vecinos, de comerciantes, de jóvenes y otras, que hemos denominado de interés y que englobaba a informantes que pudiesen tener cierta relevancia en relación con los temas investigados. Los criterios básico para la elección de las distintas entidades han sido: 1) El grado de implicación que tienen en la conservación, protección o promoción del territorio. 2) El hecho de representar a distintos segmentos de edad. 3) El hecho de representar tanto a ciudadanos nacidos en el Estado español como de fuera de él. 4) La distribución territorial de las asociaciones, para abarcar una mayor extensión del espacio urbano. A modo de ejemplo, en Lleida se han hecho entrevistas a asociaciones como la Asociación de Comerciantes de la Zona Alta, la Organización de Vecinos de Pardinyes, el Centro Social Autogestionado la Maranya o el Centro Latinoamericano de Lleida; en Tarragona, a asociaciones como la Asociación de Vecinos Progresista de Torreforta, la Asociación de Vendedores del Mercado Central de Tarragona, la Asociación de Ayuda Mutua de Inmigrantes de Tarragona o el Ateneo Cultural de Mujeres de Campclar; y en Gerona a asociaciones como el Ateneo de Acción Popular, la Asociación de Jubilados y Pensionistas de Vila-Roja, el Sindicato del Taxi o la Asociación de Vecinos de la Font de la Pólvora.

4 Aunque lamentablemente la clasificación de los delitos ha ido variando a lo largo del tiempo, la lista de aquellos que nos han ocupado es la siguiente: Homicidio doloso y asesinato; lesiones; contra la libertad; contra la libertad sexual; contra la inviolabilidad del domicilio; contra las relaciones familiares; hurtos; robo en interior de vehículos; robo con fuerza sobre las cosas; robo con violencia o intimidación; robo o hurto de vehículos, contra la salud pública; contra la seguridad del tránsito; contra el orden público. La falta de un criterio estable y homogéneo en la clasificación de las contravenciones es, desde nuestro punto de vista, un problema para la reflexión científica que podría subsanarse fácilmente desde instancias públicas. Los tirones, por ejemplo, en ocasiones se han recogido dentro de los robos con violencia e intimidación y, en otras, tenían un apartado específico. Algo parecido sucede con el robo o hurto de vehículos. 
nuestra atención en los hurtos y en los robos con violencia o intimidación y, para explicar su emplazamiento y dinámicas, los correlacionaremos, en algunos casos, con las lesiones y los delitos contra el orden público.

Estos delitos tienen una influencia considerable en la percepción de seguridad de la ciudadanía y, además, por su emplazamiento suelen estar muy relacionados, tanto con las políticas sociales, como con las de tipo espacial o de gestión urbana que se puedan articular desde diferentes instancias. De ahí la importancia de una aproximación geográfica, que podría ofrecer herramientas importantes, tanto para la intervención sobre el tejido ya existente, como para el diseño de planes a largo plazo que, si bien no son la solución de problema (dado el carácter glocal al que ya hemos aludido, así como a la complejidad de las causas que lo generan), sí pueden ayudar a disminuir su impacto y a la configuración de un entorno percibido como más seguro. Desde este punto de vista, con la búsqueda de un modelo explicativo, intentamos ir algo más allá de las formulaciones que se basan en la idea de incrementar la vigilancia natural y en la construcción de un espacio defendible (Newman, 1971, 1996; Hernando 2008) puesto que permitiría hacer previsiones y ayudar en la planificación urbana a medio y largo plazo, distribuyendo o emplazando servicios y funciones diversas. Por otro lado, obviamente, es en estas categorías delictivas en las que podría resulta más eficaz la actuación territorial.

Si atendemos al modelo ya formulado (Fraile, Bonastra, 2011), estos delitos tienden a localizarse en zonas comerciales o de ocio, en estas páginas matizaremos y afinaremos tales ubicaciones, logrando así una mayor precisión y un mayor conocimiento de sus dinámicas internas, y veremos si se cumple en las tres ciudades objeto de estudio.

Los datos cartografiados corresponden a los años 2008, 2009 y 2010 en Gerona y Lérida. En Tarragona sólo se ha trabajado con los de 2009 y 2010, pues los Mossos d'Esquadra comenzaron a desplegarse en noviembre de 2008, por lo que la estadística está incompleta. Tras la sistematización y tratamiento de la información se han elaborado, durante 2012, sendos informes, sin valoración ni análisis científico, para los Ayuntamientos, las entidades cívicas y la Policía.

\section{LOS LÍMITES DE LA INFORMACIÓN Y LA METODOLOGÍA EMPLEADA}

Numerosos autores han reiterado que no se debe confundir la estadística policial con la realidad y casi resulta ocioso volver una vez más sobre esa idea pero, a pesar de ello, convendría exponer someramente los argumentos de fondo y, a continuación, analizar algunos datos sobre la pérdida de información para situar los mapas que presentemos en su contexto.

Por un lado, es bien sabido que una parte importante de los delitos no se denuncian ni dan lugar a ningún tipo de actuación policial, por lo que no se registran de ninguna manera. Por otro, aunque sea menos frecuente, también se denuncian hechos que no han ocurrido, pero que sí constarán en las bases de datos. En ocasiones, la propia víctima ni siquiera es consciente de su situación y no sabe que está siendo objeto de un delito tipificado y denunciable, en algunos hechos «contra las relaciones familiares», por ejemplo, se da esta situación.

Tampoco debemos olvidar aquellas contravenciones perseguidas de oficio, como el menudeo en el tráfico de drogas. En tales casos las intervenciones suelen estar guiadas por políticas de carácter general y la cartografía nos habla más de éstas que de lo que sucede en 
realidad. Algo muy parecido ocurre con las estrategias puestas en marcha desde diferentes instancias, por motivos diversos, que llevan a incrementar la presión policial en determinadas zonas y distorsionan los registros de lo que ocurre.

Pero, además de estas razones, que abren una brecha entre lo acontecido y lo que aparece en las bases de datos, hay también otras concretas que tienen que ver con dificultades de la geolocalización, que son más relevantes de lo que se podría pensar en un primer momento y que obedecen, en lo sustancial, a dos tipos de problemas. Por un lado, encontramos errores $\mathrm{u}$ omisiones en el momento de registrar el hecho, ya sea por un simple olvido de la persona afectada, por el desconocimiento del lugar preciso o por fallos importantes en la anotación de la calle, número de policía etc. Por otro, aunque en menor cuantía, también sucede a veces que en la cartografía digital no aparecen calles o enclaves concretos, imposibles de recuperar con posterioridad, por lo que algunos delitos quedan sin vinculación a un lugar ${ }^{5}$.

Tabla 1

PORCENTAJE DE PÉRDIDAS EN RELACIÓN AL NÚMERO INICIAL DE DELITOS

\begin{tabular}{|c|c|c|c|c|c|c|c|c|c|}
\hline & \multicolumn{3}{|c|}{2008} & \multicolumn{3}{|c|}{2009} & \multicolumn{3}{|c|}{2010} \\
\hline & Inicio $^{1}$ & Final $^{2}$ & $\begin{array}{c}\text { Pérdida } \\
(\%)\end{array}$ & Inicio $^{1}$ & Final $^{2}$ & $\begin{array}{c}\text { Pérdida } \\
(\%)\end{array}$ & Inicio $^{1}$ & Final $^{2}$ & $\begin{array}{c}\text { Pérdida } \\
(\%)\end{array}$ \\
\hline Lérida & 7103 & 5496 & 22,6 & 7311 & 6578 & 10,0 & 7167 & 6488 & 9,5 \\
\hline Gerona & 6675 & 4477 & 32,9 & 6679 & 4613 & 30,9 & 6041 & 4600 & 23,9 \\
\hline Tarragona & 2277 & 1250 & 45,1 & 9305 & 5340 & 42,6 & 8348 & 5250 & 37,1 \\
\hline
\end{tabular}

1. Número total de delitos registrados. 2. Número de delitos restantes tras eliminar los no georreferenciados Fuente: Elaboración propia a partir de las bases de datos de los Mossos d'Esquadra.

La tabla 1 nos muestra una clara tendencia a la baja en la pérdida de puntos, pero con valores entre el 37 y el 9,5 por ciento de los registrados inicialmente, lo que lo convierte en un factor muy digno de consideración. Desde nuestro punto de vista, la toma de conciencia de semejante limitación nos conduce en dos direcciones. Por un lado, hemos de insistir en la distancia que separa la realidad de la estadística y de su representación cartográfica, lo que nos recuerda que los mapas son meros indicadores de lo que ocurre, con las limitaciones propias de tales herramientas. Por otro, esto nos reafirma en la relevancia del análisis metódico y riguroso de esta información. Con unas pérdidas sustancialmente menos significativas, un acercamiento aproximativo podría servir para bosquejar un panorama de lo que está sucediendo pero, en las actuales circunstancias, parece obvio que es imprescindible la máxima precisión para poder extraer conclusiones fiables, de ahí la importancia de estudios de este tipo, así como su generalización en ciudades de rango y tamaño comparables.

5 Somos conscientes de que el uso de instrumentos como el GPS podría reducir significativamente, en ocasiones, esta pérdida de georreferenciación, pero de momento no es una herramienta que se haya utilizado en la elaboración de las bases de datos que cartografiamos. Por otro lado, obviamente, de nada serviría en el caso de que el registro obedezca a una denuncia en la que los factores decisivos son la memoria/voluntad del denunciante y la precisión de quien registra. 
Obviamente, poco podemos decir respecto a la lógica espacial de aquello que no cabe cartografiar, pero, por el contrario, sí se vislumbran algunas regularidades en lo tocante a los delitos en los cuales las pérdidas son las mayores o las menores (Tabla 2) y que obedecen fundamentalmente a la propia idiosincrasia de la contravención.

Tabla 2

DELITOS CON LAS MAYORES Y MENORES PERDIDAS DE INFORMACIÓN POR CIUDADES*

\begin{tabular}{|l|l|l|}
\hline \multirow{2}{*}{ Lérida } & \multicolumn{1}{|c|}{ Máximos } & \multicolumn{1}{c|}{ Mínimos } \\
\cline { 2 - 3 } & Contra la libertad sexual $(18,1)$ & Contra la inviolabilidad del domicilio $(6,3)$ \\
\cline { 2 - 3 } Gerona & Hurtos $(18,4)$ & Robo con fuerza $(8,9)$ \\
\cline { 2 - 3 } & Hurto de uso del vehículo $(32,6)$ & Contra las relaciones familiares $(0)$ \\
\hline \multirow{2}{*}{ Tarragona } & Hurtos $(33,4)$ & Robo en el interior de vehículo $(7,5)$ \\
\cline { 2 - 3 } & Tirones $(58,9)$ & Contra las relaciones familiares $(12,8)$ \\
\hline
\end{tabular}

*El porcentaje, entre paréntesis, es el promedio, en cada uno de los delitos y ciudades, de los tres años de referencia Fuente: Elaboración propia a partir de las bases de datos de los Mossos d'Esquadra

Por ejemplo, los hurtos son los únicos delitos que dan niveles altos de pérdida en las tres ciudades, lo cual no hace sino confirmar su carácter, es decir, que se cometen aprovechando el descuido o la confusión, por lo que la víctima, a menudo, no sabe dónde ha sucedido o lo sabe de una manera muy imprecisa, algo parecido, aunque con matices, podría decirse del hurto de uso del vehículo o, incluso de los tirones

El otro extremo también presenta un panorama bastante coherente. En Gerona y Tarragona dan mínimos los delitos contra las relaciones familiares y el robo en interior de vehículo. En el primer caso, el número de hechos ha sido bastante reducido y es fácil suponer que, si se llega al punto de la denuncia, por lo general, habrá una clara determinación y por lo tanto no se perderá la información sobre el domicilio. Algo parecido cabe pensar del robo en interior de vehículos, ya que cuando lleva a la víctima hasta completar la denuncia, debe de haber motivos de diferente índole, como el recurso al seguro o la cuantía de lo sustraído, que hacen que tenga un especial interés en que los hechos consten con precisión. En el caso de Lérida, los mínimos los encontramos en infracciones estrechamente vinculadas a lugares concretos.

Finalmente, conviene dar cuenta de cómo hemos abordado la cartografía de estos fenómenos. Hemos utilizado el CrimeStat III, un programa de estadística espacial para el análisis locacional de los hechos delictivos, que explicamos muy someramente a continuación.

El Nearest Neighbour Index (Índice del Vecino más Cercano) calcula el nivel de aleatoriedad en la distribución espacial de un fenómeno determinado, como por ejemplo un delito concreto. Cuando adquiere el valor 1 indica que la distribución es aleatoria, cuando es menor quiere decir que hay concentraciones superiores a las que cabría esperar en una de ese tipo. Este cálculo, que no recogemos en estas páginas, nos ha permitido, antes de la cartografía, hacernos una idea bastante clara sobre el grado de concentración que presentará cada categoría, con el objetivo de prever si habrá lugares con agrupaciones significativas. El 
paso siguiente ha sido cartografiar estos datos empleando la función Nearest Neighbour Hierarchical Spatial Clustering (Clustering de Jerarquización Espacial del Vecino más Cercano, NNHSC), que dibuja un polígono, los vértices del cual son fenómenos de la distribución, que cierra aquellos puntos que tienen una proximidad entre sí superior a la que se daría en el caso de ser aleatoria (lógicamente puede crear varios polígonos). A continuación se genera, en el interior de cada uno de ellos, una elipse que contiene los hechos con un mayor grado de concentración. Para delimitar los polígonos y las elipses se puede señalar el porcentaje de fenómenos que cada uno de estos tiene que circunscribir. Así, hemos hecho pruebas con diferentes valores como el $10 \%$, el $5 \%$ o el $2,5 \%$ de los acontecimientos, que respectivamente representarían, en el caso de que se dieran los mencionados índices de concentración y tuvieran representación cartográfica, Hot Spots (zonas calientes) de mayor a menor importancia. Finalmente, hemos añadido a los mapas resultantes una capa de información en la cual se muestran todos los puntos con objeto de representar también los acontecimientos que quedan fuera de las elipses que dibuja el NNHSC.

\section{ANÁLISIS DE LOS DATOS EMPÍRICOS}

Para facilitar el análisis y la aparición de regularidades hemos optado por plantearlo a partir de las contravenciones, señalando los lugares relevantes en cada una de las ciudades. En aras de la síntesis, y dado que al tratarse de delitos con una lógica estructural los puntos se repiten con pequeñas variaciones a lo largo de los años, presentaremos únicamente los mapas de 2010, para mostrar en ellos los espacios significativos. Tampoco hemos incluido la cartografía de las lesiones ni de los delitos contra el orden público y hemos resumido su correlación con los hurtos en una tabla.

\section{IV.1. Hurtos}

El hurto es el delito con una lógica locacional estructural más clara. Suele encontrarse diseminado por toda la ciudad, pero presenta además ciertos emplazamientos de alta densidad y permanencia.

En casi todos los casos, se trata de sitios muy concurridos que, por el tipo de actividad que en ellos se realiza, propician el despiste o la distracción. Aunque los enclaves que tienen tales características son de índole muy variada, podemos distinguir dos categorías: las áreas más o menos vinculadas a un punto o establecimiento concreto y su zona colindante, y otras más amplias, y quizás menos definidas o más difusas, pero con afinidades que pueden ir desde su funcionalidad, a ciertos aspectos estructurales desde el punto de vista urbanístico (Fraile y Bonastra, 2011: 132).

Si centramos nuestra atención en la primera, encontramos en las tres ciudades lugares significativos, relacionados con puntos o establecimientos singulares, donde se aprovecha la confusión y el despiste para perpetrar el delito: hipermercados o centros comerciales, mercados periódicos («mercadillos») y estaciones de trenes o autobuses.

Los centros comerciales y los hipermercados (A en las figuras) están diseñados para permitir el flujo de los clientes y estimular el consumo, cosa que según Manzo (2005: 86) es un factor disuasorio para la perpetración de ciertos delitos, pero diferentes estudios, realizados 
en los años 80 en varias ciudades inglesas por Poyner y Webb (1987), explican cómo las grandes superficies comerciales suelen ser un importante polo de atracción de los hurtos. Un buen ejemplo, que ilustra esta afirmación, lo tenemos en la ciudad inglesa de Sheffield, en cuyo centro urbano hubo un descenso porcentual notable de delitos en un año (pasando del $24 \%$ al $10 \%$ ) como consecuencia de la inauguración del centro comercial periurbano de Meadowhall (Willes, Costello, 2000: 46). Idéntica capacidad de atracción se había manifestado en Lérida en 2007, y se continúa mostrando en la actualidad, pues encontramos una alta concentración de hurtos en el centro comercial intraurbano que contiene el hipermercado Carrefour, y sus aledaños, situado en un el Paseo de Ronda, una de las vías rápidas de la ciudad que coincidía anteriormente con la carretera N-II. El modelo se repite en Gerona gravitando, por un lado, en torno al polígono comercial situado en la entrada sur de la ciudad en el que encontramos los almacenes Carrefour, Bauhaus y Media Markt y el restaurante Mc Donalds, y, por otra parte, el hipermercado Hipercor. Ambos enclaves están ubicados en la mitad sur de la ciudad sobre la carretera de Barcelona, el eje que la cruza de sur a norte. En Tarragona, también vemos idéntica dinámica, propiciada por el centro comercial Parc Central, situado entre la Avenida Roma (que coincide con la carretera de Valencia), la avenida Vidal i Barraquer, y la muy comercial Avenida Ramón y Cajal.

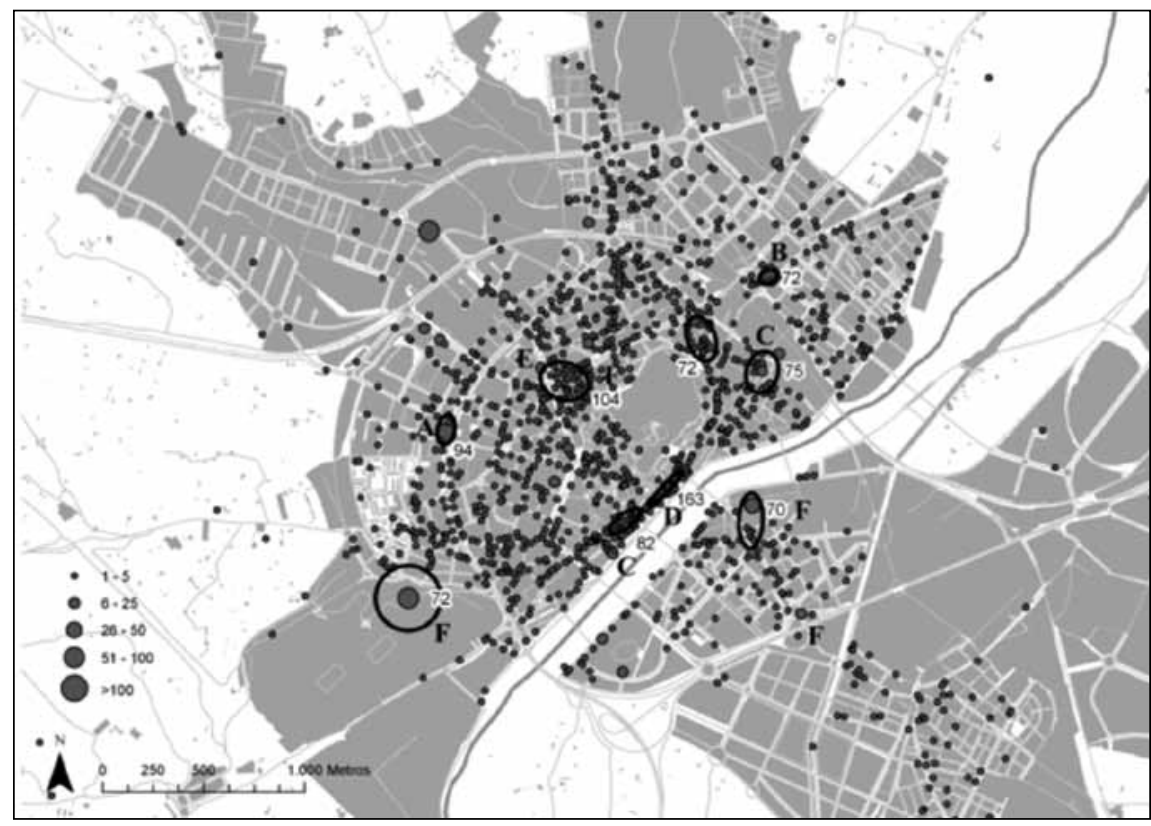

Fuente: elaboración propia a partir de los datos de las Mossos d'Esquadra.

En este contexto conviene observar que los centros comerciales, son lugares de uso público, pero con normas y titularidad privada, por lo que no son propiamente un espacio 
público y distan mucho de aquellos que podrían considerarse de calidad ${ }^{6}$, aunque en muchos casos intenten emularlos (Díaz, 2005). Precisamente su monofuncionalidad invita a consumir y la pobreza de las relaciones sociales que allí se establecen, tendentes al anonimato y la uniformidad (Suau y Font, 2005: 254), también contribuyen a la comisión de hurtos.

Los mercados ambulantes periódicos (B en las figuras) tienen rasgos que los emparentan con los centros comerciales, puesto que en ellos se conjugan la aglomeración, el usuario despistado y un alto grado de desorden. Exponente de ello es, en Lérida, el mercado dominical del barrio de Pardinyes, en Gerona el que se organiza en el parque de la Devesa y en Tarragona el que funciona los martes y jueves en la Rambla Nova y el dominical del barrio periférico de Bonavista.

Los principales nodos y las cabeceras y finales de línea de las redes de transporte público (C en las figuras) suelen ser lugares de alta concentración de delitos (Hernando, 2001-2002: 203). En Lérida, Fraile y Bonastra (2011: 132-134) ya localizaron como lugares de elevada densidad de hurtos la estación de autobuses de línea y la de ferrocarriles, imbricadas ambas en el eje comercial de la ciudad, para el periodo 2005-2007. Para el lapso temporal que ahora nos ocupa vemos que ambos puntos vuelven a ser relevantes desde este punto de vista. En Gerona, ocurre lo mismo con ambas estaciones, que comparten espacio en el centro de la ciudad, igual que sucede en Tarragona aunque de una manera algo más diseminada.

En la otra categoría, propia de zonas más amplias, diferentes de las vinculadas a establecimientos o puntos concretos, encontramos las áreas comerciales y las de ocio, ambas más difusas que las anteriores. Comenzaremos por las primeras. En Lérida, Gerona y Tarragona hay varios espacios de este tipo, con una centralidad significativa y una intensa terciarización, en los que se puede mezclar el comercio, ya sea de «boutiques» o de gran superficie, y el entretenimiento. Tienen, además, una gran accesibilidad (Hernando, 2001-2002: 205). Como podemos imaginar, algunas de estas zonas están en los centros históricos de las ciudades que nos ocupan (D en las figuras), tal es el caso del eje comercial de Lérida y del que discurre por la Rambla del Barri Vell y la calle de Santa Clara en el barrio del Mercadalde Gerona. Como explica Troitiño (2003: 132-135), además de ser una referencia simbólica y cultural, los centros históricos suelen ser ecosistemas muy precarios que a menudo están sujetos a múltiples presiones que pueden romper su equilibrio. Así, algunos de los problemas que los amenazan son «la excesiva terciarización, la pérdida de vida social, la infrautilización residencial o la turistización», fruto de la competencia entre las diversas funciones en un suelo limitado. En tal sentido, uno de los mayores retos con el que se encuentran las autoridades locales es el mantenimiento de la multifuncionalidad en estas áreas centrales de la ciudad, adquiriendo un carácter determinante la residencial, garante de la heterogeneidad social (Ibid: 133).

6 Según Suau y Font (2005: 246), las características para que un espacio público pueda ser considerado de calidad son las siguientes: tener poder de convocatoria; tener intensidad y riqueza en las relaciones sociales; la plurifuncionalidad; la continuidad con el espacio urbano de su entorno; la accesibilidad sin restricciones físicas, legales ni temporales; ser seguro por su configuración; tener un diseño arquitectónico digno y acorde con el entorno; ser flexible y ser democrático. 
Figura 2

DENUNCIAS POR HURTO EN GERONA EN 2010 (MODE Y NNHSC AL 2,5\%)

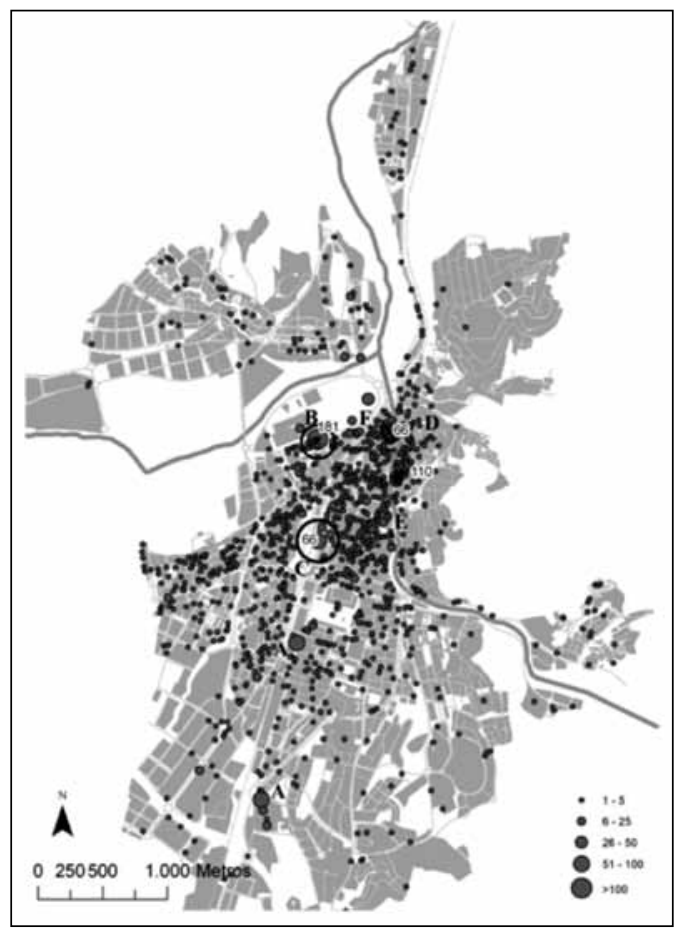

Fuente: Elaboración propia a partir de los datos de las Mossos d'Esquadra.

Nos encontramos, pues, ante dos ejes comerciales de centros históricos bastante diferentes. El de Lérida es un conjunto urbano, formado por varios kilómetros de calles dedicado fundamentalmente al comercio al detalle, las sedes de distintas instancias de la administración y despachos de profesionales liberales. Además, ha cumplido históricamente la función de lugar de paseo y socialización de los habitantes de la ciudad y de los núcleos de su área de influencia. Es un espacio muy terciarizado, con una función residencial prácticamente nula en tramos importantes de la calle (Bellet y Vilagrasa, 2001; Vilagrasa et al., 1996), por lo que se producen vaivenes en la intensidad de su uso a tenor de los horarios de atención al público y, lógicamente, los hurtos se cometen en esa franja temporal ${ }^{7}$. Obviamente esto ocurre, en primer lugar, por tratarse de los momentos en los que se crea el ambiente de distracción que los propicia. Pero por otra parte, conviene también tener en cuenta que el eje comercial leridano solamente ocupa una porción del centro histórico y buena parte del resto se encuentra sumida desde hace años en un proceso de degradación urbana y desestructuración social (Bonastra, 2008). Lo demuestran la casi

7 Según la web del eje comercial, que pertenece a la Federación de Asociaciones de Comerciantes del Eje Comercial de Lérida (FACEC), hay algo más de 400 comercios que visitan diariamente entre 15.000 y 25.000 personas dependiendo de la época del año. 
monofunción residencial del vecindario, el progresivo cierre de los comercios tradicionales (Bellet et al., 2005) y el importante contingente de inmigrantes que lo habitan atraídos por los alquileres baratos del precario parque inmobiliario ${ }^{8}$.

El centro histórico gerundense tiene unas características totalmente diferentes, puesto que en él, al contrario de lo sucedido en Lérida, se ha producido una recuperación por parte de la ciudadanía y de las instituciones que empezó con el Pla Especial del Barri Vell de 1983 y que, además de todas las intervenciones técnicas en las infraestructuras urbanas, puso el acento en evitar la ruina y el abandono tanto de grandes edificios antiguos, que se han convertido en equipamientos de todo tipo (desde la sede de las diferentes instancias de gobierno hasta el rectorado y diversas facultades de la Universidad), como del parque de viviendas, que ha sido renovado en gran medida (Nadal, 2003) ${ }^{9}$. Como consecuencia, en algunos sectores del barrio incluso se puede llegar a hablar de gentrificación. El circuito que discurre por las calles paralelas a ambos lados del río (fundamentalmente la Rambla de la Llibertat y la Calle de Santa Clara), se peatonalizó para crear un área libre de coches que estimulara, por sus características ambientales, la vida comercial, que en los años anteriores a todas estas reformas mostraba claros síntomas de estancamiento e incluso de recesión (Birulés, 2003). Como ocurre en Lérida, la relación entre la comisión de delitos y los horarios de apertura de comercios y demás servicios es bastante evidente.

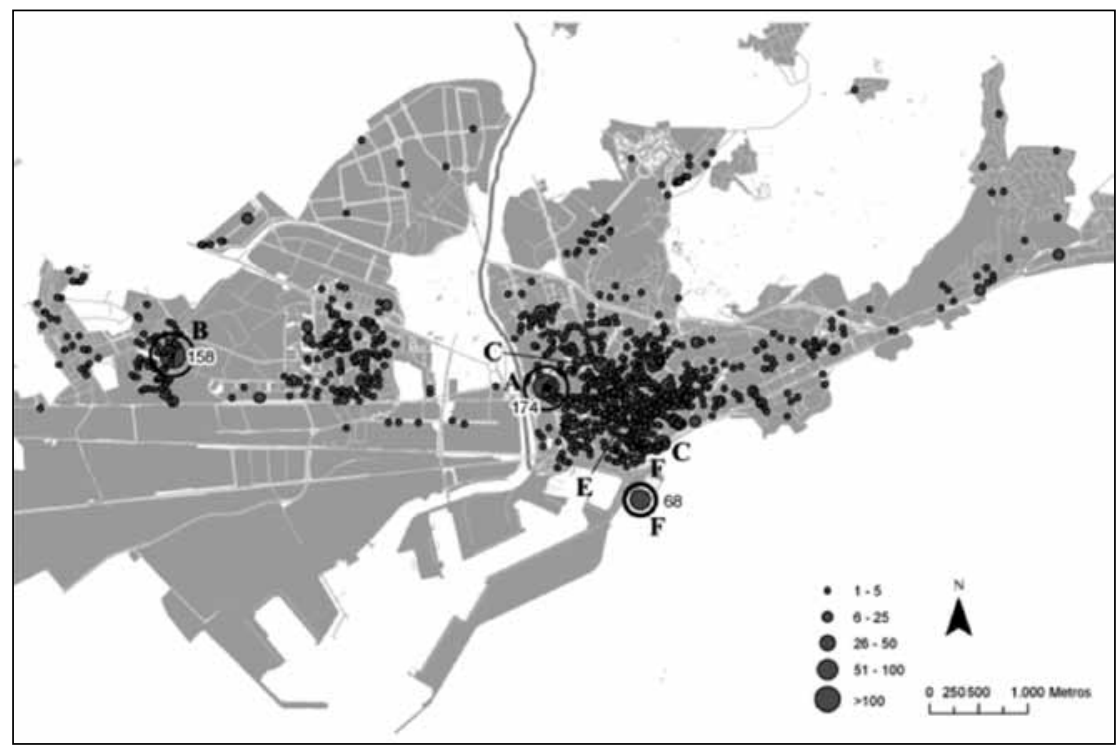

Fuente: Elaboración propia a partir de los datos de las Mossos d'Esquadra.

8 En 2010, en la sección censal 4.1, que se corresponde con la parte más degradada del centro histórico, un 51 '7\% de los habitantes eran inmigrantes. Datos del INE, padrón continuo de habitantes.

9 Para una imagen de conjunto de este proceso es interesante ver los mapas de las páginas 61 y 63 de ese artículo. 
Por el contrario, el centro histórico de Tarragona no alberga un eje como los anteriores, ya que cuenta con una única calle realmente comercial (Oliveras, 2012: 129), la calle Mayor. Ésta tiene unas dimensiones reducidas y una afluencia de público bastante limitada entre semana y fuera de la temporada turística, por lo que no se puede considerar propiamente un eje comercial. Por estas razones, la concentración de hurtos es más baja que en las zonas similares de Lérida y Gerona.

Fuera de los centros históricos, también encontramos otras áreas comerciales (E en las figuras) con concentraciones significativas de hurtos. Se trata de zonas de alta centralidad y accesibilidad en las que hay una mayor diversificación funcional y donde suele predominar la residencial, que se mezcla con la comercial y la de ocio, ya sea en su vertiente de restauración como de ocio nocturno. En Lérida tiene relevancia la conocida como Zona Alta con el centro en la plaza RicardVinyes, y que comprende gran parte de las calles colindantes. En Gerona, es significativa el área correspondiente al barrio del Eixample Nord. En Tarragona pasa lo mismo en el eje comercial situado a ambos lados de la Rambla Nova, tanto al norte, en la zona de la plaza Verdaguer y las calles Sant Agustí, Comte de Rius y Emperador Agustí, como al sur de la misma, en el espacio entre la calle Unió y el mercado, situado en la calle Gobernador González.

La otra categoría de lugares relativamente difusos, relacionados con los hurtos, es la de los vinculados a los locales de ocio nocturno ( $\mathrm{F}$ en las figuras). Esta es una relación conocida que nos proporciona múltiples ejemplos, como el de Polonia, donde una encuesta entre de los clientes de bares y clubs nocturnos mostraba que el $70 \%$ habían sido víctimas de hurtos (Kubacki et al., 2007: 959). Igualmente, a principios de la década pasada el Home Office inglés publicó una serie de memorias en que se estudiaban los efectos del uso de alcohol y sustancias estupefacientes por parte de los jóvenes. En algunas de ellas queda bien clara la correlación entre el estado de borrachera y la comisión de actos ilícitos o la conducta desordenada, como los hurtos, las peleas o los hechos incívicos (Richardson y Budd, 2003: 42). Lobo y Guimarães (2013) establecen el mismo vínculo para el centro histórico de la ciudad brasileña de Belén. Por esta razón, además de buscar los puntos de alta incidencia de hurtos en las tres ciudades hemos cotejado esta información con la cartografía relativa a lesiones y delitos contra el orden público, generada en el marco de esta investigación, que aquí omitimos en aras de la síntesis.

De este modo, tenemos que, en Lérida, los hurtos relacionados con el ocio se concentran en varios puntos: el parque de los Campos Elíseos, en el que se celebran ferias, conciertos y acontecimientos deportivos y en el que existe, además, un «night-club», el River Café; la discoteca Larida, situada en la colina de Gardeny, y el área de ocio que se encuentra en la intersección de la carretera N-II y la avenida de las Garrigas, compuesta por la bolera, un restaurante y la discoteca Pachá. Conviene decir que todos estos lugares ya se habían revelado anteriormente como puntos significativos en el estudio citado. En Gerona sigue esta lógica territorial el eje que enlaza la plaza de la Indepenencia con el parque de la Devesa por la calle Figuerola y las adyacentes, un continuo de restaurantes y bares que se ha consolidado en los últimos años. En Tarragona aparece con claridad la línea correspondiente a la calle Apodaca y colindantes, que es una zona de ocio en la que la juventud pasa las primeras horas de la noche antes de desplazarse hasta los locales del puerto deportivo, lugar, éste último, que se nos presenta como un punto con una importantísima concentración de hurtos, aunque, a partir de 2012, ha ido perdiendo progresivamente esta capacidad de atracción, como consecuencia del cierre de la mayoría de estos establecimientos. 
Tal como hemos señalado más arriba, hemos estudiado la correlación, en estos enclaves, entre los hurtos y las lesiones o los delitos contra el orden público, que resumimos en la Tabla 3.

Tabla 3

ZONAS Y GRADO DE COINCIDENCIA DE CONTRAVENCIONES RELACIONADAS CON EL OCIO

\begin{tabular}{|c|c|c|c|c|c|c|c|c|c|c|}
\hline Ciudad & Zona & & 2008 & & & 2009 & & & 2010 & \\
\hline \multirow{4}{*}{ Lérida } & & HHurtos & LLesiones & OO. Público & Hurtos & LLesiones & O. Público & Hurtos & Lesiones & O. Público \\
\hline & Pacha/Bowling & & & & & & & & & \\
\hline & Campos Elíseos & & & & & & & & & \\
\hline & Larida & & & & & & & & & \\
\hline Gerona & Independencia/Figuerola & & & & & & & & & \\
\hline \multirow{2}{*}{ Tarragona } & Apodaca & & & & & & & & & \\
\hline & Puerto Deportivo & & & & & & & & & \\
\hline
\end{tabular}

Fuente: Elaboración propia a partir de las bases de datos de los Mossos d'Esquadra.

Todo ello nos reafirma en la idea de que este modelo locacional tiene una lógica relativamente distinta del vinculado a la función comercial y esta es una característica estable que se repite en las tres ciudades, una de cuyas manifestaciones más claras es el hecho de que los delitos, al contrario de los acaecidos en aquellas zonas, se dan en la franja nocturna.

\section{IV.2. Robos con violencia o intimidación}

Los robos con violencia o intimidación también presentan una lógica locacional estructural y, al encontrarse entre los delitos considerados violentos, han sido más estudiados que los hurtos, en las dos últimas décadas en ciudades europeas y americanas, usando metodologías principalmente cuantitativas, lo que ha dado lugar a algunas generalizaciones dignas de ser mencionadas. Respecto a su distribución espacial, algunos autores han señalado que suelen situarse en los barrios más céntricos de la ciudad (Ceccato, Oberwittler, 2008: 189), (Sahbabaz, Hillier, 2007: 22-06), (Nelson et al., 2001) y tienden a perpetrarse en las franjas nocturnas (Smith, 2003: 36), relacionándose en muchos casos con el cierre de comercios (Hernando, 2001) y con la existencia de locales de ocio ${ }^{10}$. Es decir, ciertas funciones urbanas propician la concentración de robos con violencia, que, como nos muestran Sahbaz y Hillier (2007: 022-06), están vinculadas al comercio al detalle, a los servicios en general y a los principales nodos de las redes de transporte. Parecidos resultados nos ofrecen Ceccato y Oberwittler (2008: 189).

10 Según los datos presentados por Smith (2003: 38) para diversas ciudades inglesas, el $61 \%$ de los robos con violencia o intimidación se cometen en espacios público, ocurriendo el 50\% del total en la calles, el 16\% se producen dentro o alrededor de locales comerciales (que incluyen comercios al detalle, restaurantes, pubs, night-clubs, licorerías y bancos). Por su parte, Nelson et al. (2001: 263), también llegan a la conclusión de que, aunque no es el único factor determinante, la acumulación de pubs y clubs nocturnos incrementa la posibilidad de aparición de delitos violentos callejeros. 


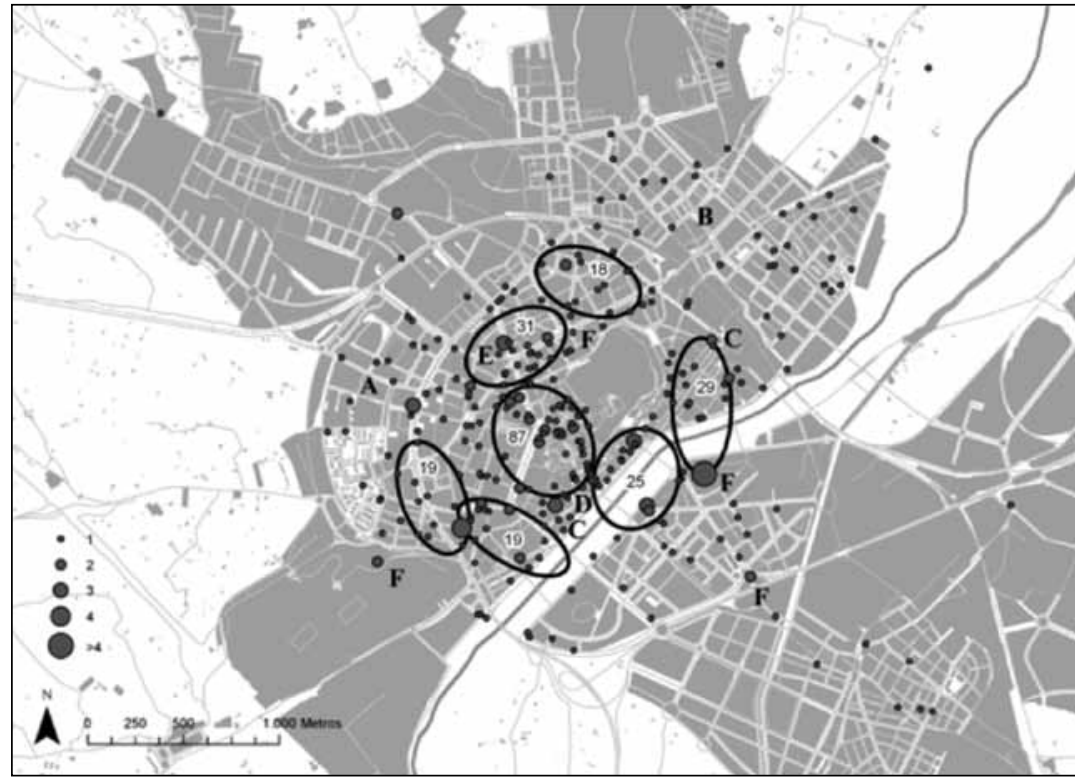

Fuente: Elaboración propia a partir de los datos de las Mossos d'Esquadra.

Antes de precisar la localización de estos delitos en nuestras ciudades de referencia conviene señalar que hay una gran diferencia cuantitativa entre los hurtos (la contravención más numerosa en las tres ciudades), y los robos con violencia o intimidación, que representan entre el $8 \%$ y el $15 \%$ de los primeros a lo largo de todo el periodo, lo que hace que sus patrones de localización sean menos rotundos. Pero, además, hay que dar cuenta de algunas peculiaridades que los separan del modelo que parecería desprenderse de los estudios anteriormente mencionados. Nuestra investigación muestra que hay una cierta coincidencia en la localización de ambos delitos, hurtos y robos con violencia, pero además, y quizás sea lo más revelador, el horario en que se comenten los segundos es mayoritariamente el diurno y no la franja nocturna como cabría esperar. El bajo nivel de violencia de la delincuencia en el entorno que estamos analizando nos permite suponer que, en tales circunstancias, estos robos no son realmente una contravención específica sino, más bien, son hurtos que se han complicado $^{11}$, por lo que el autor ha recurrido a una cierta agresividad para concluirlo o para darse a la fuga, de ahí las dudas sobre un carácter propio y diferenciado y, por el contrario, nuestra afirmación de que su comportamiento espacio/temporal está estrechamente emparentado con el de los hurtos. Tal dinámica ya se había mostrado en Lérida en el periodo 20052007. Tampoco debemos olvidar los riesgos de una excesiva generalización que a menudo ha llevado a hablar de la ciudad occidental sin considerar que hay divergencias notables entre

11 Algo parecido explican Nelson et al. (2003: 262), para el caso de ciudades medianas inglesas como Cardiff o Worcester. 
algunas propias del norte europeo o del ámbito anglosajón y las del sur, entre otras cosas por la diferente intensidad del uso del espacio público. De todos modos, cabe afirmar que estos resultados son extrapolables a ciudades de otros ámbitos geográficos y con niveles de criminalidad más importantes. Lobo y Guimarães (2013), por ejemplo, muestran una clara correlación entre hurtos y robos con violencia en las áreas de concentración comercial de la ciudad de Belén.

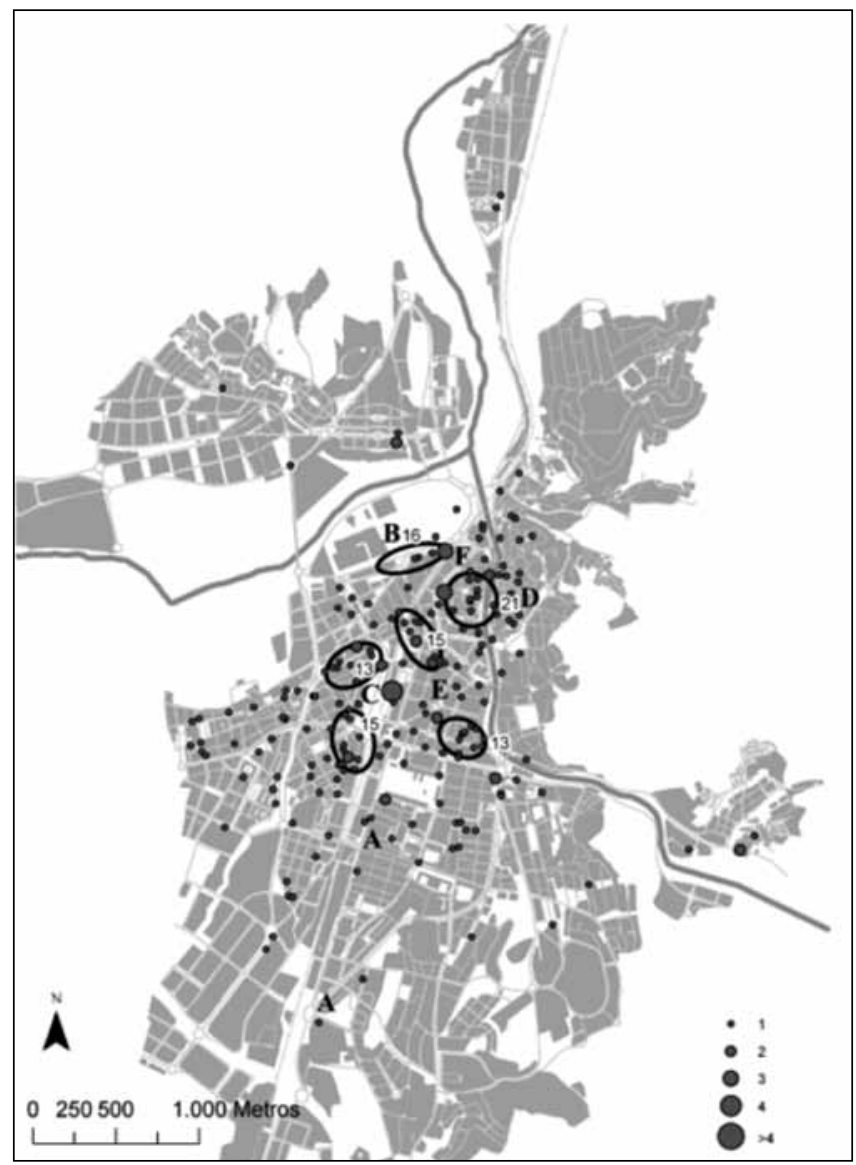

Fuente: Elaboración propia a partir de los datos de las Mossos d’Esquadra.

Un primer aspecto a señalar es que los Centros Comerciales y los mercados periódicos son mucho menos significativos, como polos de atracción, cuando se trata de este delito. Por lo demás, las pautas, como hemos dicho, son bastante coincidentes y, una vez más, volvemos a encontrar los ejes comerciales situados en los centros históricos de Lérida y Gerona. Tarragona queda de nuevo fuera por carecer, como explica Oliveras (2012: 129), de un enclave de 
este tipo en la antigua ciudad amurallada. En ambos casos hay altas concentraciones de robos con violencia y, como ya se ha puesto de relieve, de hurtos, acaecidos mayoritariamente en el horario comercial.

Igualmente, hemos de referirnos, de nuevo, a las áreas comerciales situadas en los ensanches, en las que suele haber una cierta mezcla con el ocio y un mayor peso de la función residencial. Responden a este perfil la Zona Alta de Lérida, el eje comercial del Eixample Nord de Gerona, y la porción del eje comercial situado al sur de la Rambla Nova de Tarragona. En este caso vuelve a ser manifiesta la mayor ocurrencia de delitos en horario comercial, como también sucede en las estaciones de autobuses y de ferrocarriles, que aparecen con altibajos según el año en las tres ciudades.

Finalmente, comparten espacio con los hurtos los robos con violencia que se perpetran en algunas zonas de ocio, como los Campos Elíseos de Lérida y los alrededores de la calle Apodaca o el puerto deportivo de Tarragona, lugares en los cuales se aprecia una cierta tendencia a la especialización nocturna, sobre todo en Tarragona aunque, tal como dijimos, este enclave ha ido perdiendo capacidad de atracción desde 2012.

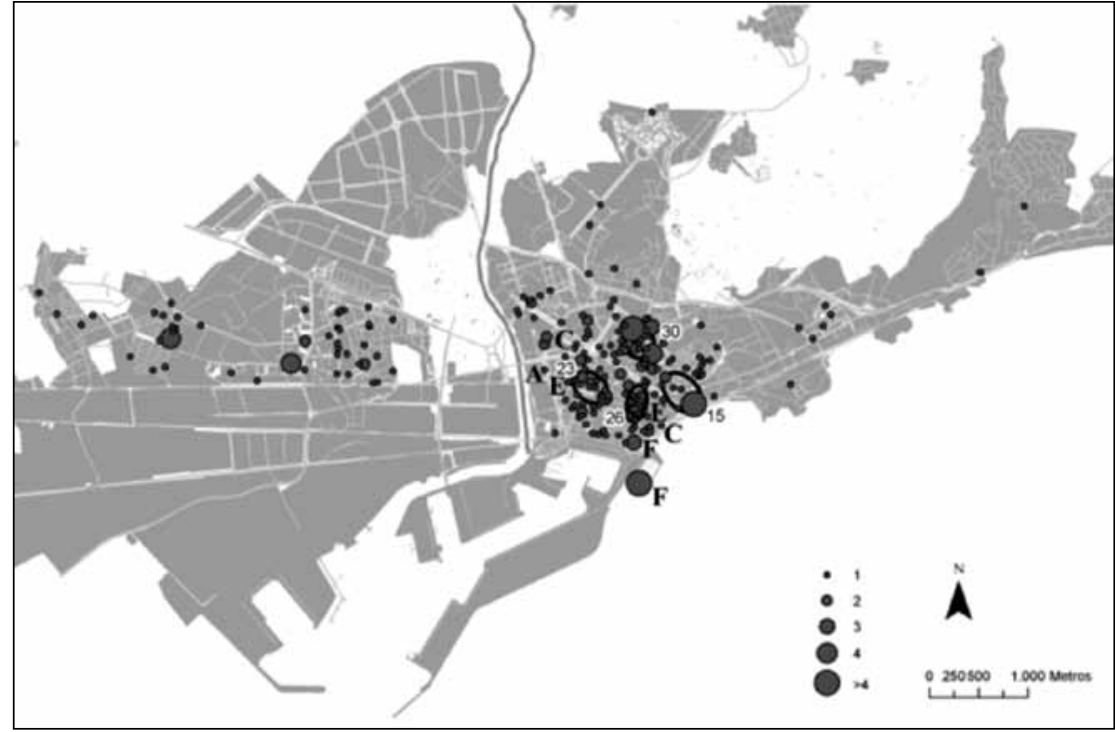

Fuente: Elaboración propia a partir de los datos de las Mossos d'Esquadra.

Cabría también destacar algunas zonas con una concentración significativa de robos con violencia no coincidentes con las de hurtos. Por lo general se trata de áreas residenciales, como la de la calle de Santa Eugènia en su confluencia con el parque central de la ciudad de Gerona. En Tarragona destaca la comprendida entre las calles del Marqués de Montoliu, Catalunya, María Cristina,Estanislau Figueres y Sant Antoni Maria Claret, que corresponde, en gran parte, al Barrio Nou Eixample Nord. Se trata de una zona urbanísticamente muy 
heterogénea y poco estructurada, donde se mezcla la trama ortogonal con otra asentada en un cierto desorden, con bloques exentos rodeados de pasillos laterales, algunos callejones sin salida, plazas cuasi cerradas, algunos pasillos cubiertos que comunican dos calles a través de edificios, etc. En cuanto al tipo de construcciones, encontramos desde bloques de vivienda de una cierta altura (8 o 9 plantas) a casas unifamiliares, algunas promociones de vivienda social, varios colegios que ocupan grandes extensiones de terreno e incluso una pequeña ciudad jardín construida en los años 40 . Se observa allí una cierta vida comercial dispersa que promueve el vaivén de personas que suponemos que está relacionado con esta concentración de robos.

\section{CONCLUSIÓN}

Tal como dijimos al principio de estas páginas, uno de nuestros objetivos prioritarios en ellas ha sido comprobar la validez del modelo de emplazamiento delictivo que habíamos establecido a partir del trabajo empírico realizado en la ciudad de Lérida, cotejándolo con lo sucedido en Gerona y Tarragona y, a su vez, afinar las categorías espaciales que establecimos en su momento.

En este artículo nos hemos ocupado de los hurtos y de los robos con violencia o intimidación, contravenciones ambas que englobamos dentro de aquellas con una lógica locacional estructural y, por tanto, con una tendencia a la estabilidad en su ubicación, vinculada a ciertos rasgos o funciones urbanas.

En términos generales cabe afirmar que este carácter estructural se da en las tres ciudades lo cual, además, consideramos que es extensible a una buena parte de ciudades europeas de rango y tamaño semejantes. Por otra parte, aparecen regularidades significativas que nos permiten precisar el tipo de lugares que se relacionan con estos delitos.

Respecto a los hurtos, hemos mostrado que hay dos grandes categorías relativas a los sitios que los atraen y estabilizan (Tabla 4). Por un lado tenemos aquellos espacios dependientes de un punto concreto y, de una manera limitada, su entorno más próximo. En este grupo, a su vez, hemos detectado tres tipos de lugares que, de manera regular, se repiten en las tres ciudades: Centros comerciales, mercados periódicos («mercadillos») y estaciones de trenes y autobuses.

Tabla 4

CATEGORÍAS DE ENCLAVES EN LA LOCALIZACIÓN DE HURTOS Y ROBOS

\begin{tabular}{|l|l|l|}
\hline Tipo de enclave & Lugares & Subcategorías \\
\hline \multirow{3}{*}{$\begin{array}{l}\text { Puntos concretos y } \\
\text { entorno inmediato }\end{array}$} & Centros comerciales & \multirow{2}{*}{} \\
\cline { 2 - 2 } & Mercados periódicos («Mercadillos») & \\
\cline { 2 - 3 } & Estaciones de Tren/Autobús & \\
\hline \multirow{2}{*}{$\begin{array}{l}\text { Áreas amplias con } \\
\text { Fronteras difusas }\end{array}$} & Áreas comerciales & Situadas en Centros Históricos \\
\cline { 2 - 3 } \cline { 2 - 3 } & Áreas de ocio & Situadas en Ensanches \\
\hline
\end{tabular}

Fuente: Elaboración propia. 
La segunda categoría está compuesta por espacios más amplios, con unas fronteras más difusas que en el caso anterior, dentro de la que podemos distinguir dos subgrupos: las áreas comerciales y las de ocio. Las primeras, a su vez, dan lugar a dos modelos relativamente distintos: aquellas zonas incluidas en centros históricos, por lo general muy terciarizadas y en un equilibrio relativamente precario y otras crecidas en ensanches o partes relativamente nuevas de la ciudad, donde, a menudo, se combinan diversos servicios como bares, restaurantes etc., además de la vivienda.

Finalmente, en este grupo de fronteras relativamente difusas encontramos las zonas de ocio, en el sentido más estricto, que, tal como hemos dicho, tienen unas dinámicas relativamente distintas de las de carácter más comercial y, quizás, su rasgo más distintivo sea la vinculación con los delitos contra el orden público y las lesiones, así como su desplazamiento hacia el horario nocturno. Tal peculiaridad debería ser tenida en cuenta por las autoridades municipales en el momento de diseñar estrategias de intervención urbana que distribuyan funciones y tareas.

Los robos con violencia o intimidación, en términos generales, y en el tipo de ciudades que nos ocupa, comparten bastantes lugares con los hurtos, pero lo que resulta más revelador es el hecho de que, en contra de lo que han mostrado ciertos estudios realizados en otras ciudades, no se comenten en el horario nocturno sino, por el contrario, durante el día y, en lo sustancial, coinciden bastante en sus rasgos espacio/temporales con los hurtos. Dado que estamos estudiando entornos urbanos con niveles bajos de violencia, cabe suponer, como ya hemos señalado, que estos delitos no configuran una categoría específica, claramente diferenciada de la anterior, sino que, más bien, se trata de hurtos que se han complicado, impeliendo al agresor a recurrir a la amenaza para concluir el robo o darse a la fuga, de ahí las similitudes entre ambas contravenciones.

A partir de estas regularidades de carácter territorial, que aparecen en las tres ciudades, cabría preguntarse por las conclusiones relativas a las políticas de intervención urbana que emanan de ellas. A continuación las planteamos de manera esquemática:

1. La excesiva especialización funcional (ya sea comercial, de ocio o la terciarización en general) degrada el espacio público, empobrece su uso y lo hace más vulnerable a una amplia gama de ataques y, entre ellos, está la proliferación de ciertos delitos, como los que nos han ocupado en estas páginas.

2. Si la afirmación anterior es cierta en términos generales, lo es especialmente cuando se trata de zonas incluidas en centros históricos, ya que son lugares especialmente sensibles, a menudo en equilibrios precarios, por lo que es especialmente importante ser muy minucioso en la asignación y reparto de tareas.

3. En este proceso de delimitación de funciones urbanas es particularmente importante el papel asignado a la residencial, buscando la heterogeneidad y complejidad que propicie la integración y la cohesión social. Igualmente se han de contemplar todas aquellas actividades sociales que avancen en la misma dirección.

4. Todo ello nos lleva a afirmar la necesidad de un espacio público de calidad, lo que depende tanto de aspectos morfológicos, como la relación entre las viviendas y la calle ${ }^{12}$,

12 Conocido como grado de «constitución» (constitutedness) de las calles (Hillier y Hanson, 1984: 92). Éste tiene que ver con la manera en la que las entradas de los edificios están conectadas a la calles. Una calle tendrá un 
la continuidad con su entorno espacial o la dignidad de sus componentes arquitectónicos, como sociales o relativos a la planificación, como su plurifuncionalidad, su flexibilidad o la riqueza de las relaciones personales que se dan en él.

En definitiva, habría que crear entornos vivibles por los ciudadanos, respetando, valorando y potenciando su heterogeneidad y complejidad. Se trataría, por tanto, de propiciar espacios cuyos rasgos los configuren como algo complejo y rico, más en la línea de los SafeScape (Zelinka \& Brennan, 2001) que en la de los espacios defendibles, cuya propia calidad, así como la de los vínculos sociales que en ellos se establecen, estimulen un uso variado e intensivo.

Somos conscientes de que tal configuración territorial no es, ni pretende ser, la solución al problema de la delincuencia, que obedece a causas complejas, pero sí serviría para crear espacios menos vulnerables a ciertos ataques y, entre ellos, la proliferación de ciertos delitos, donde habría que estimular un uso enriquecedor que fomentase la cohesión social y que redundará en su percepción como un lugar seguro.

\section{REFERENCIAS}

BAUMAN, Z. (2003): City of fears, city of hopes. London, Goldsmith's College.

BECK, U. (2006): La sociedad del riesgo global, $2^{\mathrm{a}}$ ed. Madrid, Siglo XXI.

BELLET, C. y VILAGRASA, J. «Diferenciaciósocioespacial de la ciutat de Lleida» en Revista Catalana de Sociologia, $\mathrm{n}^{\circ}$ 14, 2001, 13-42.

BELLET, C., HERRERA, N., MÒDOL, J.R. y CLAVEL, M. (2005): Atles comercial de Lleida. Lleida. Turisme de Lleida, Ajuntament de Lleida.

BIRULÉS, J.M. (2003): «Possibilitats i límits de la rehabilitació. La ciutat antiga de Girona» en Girona, 20 anys del Pla Especial del Barri Vell (1983-2003)(Birulés, J.Mª,coord.). Girona. Ajuntament de Girona, 9-32.

BONASTRA, Q. (2008): «¿Calles peligrosas? Morfologías del delito» en Scripta Nova. Revista Electrónica de Geografía y Ciencias Sociales, vol. XII, núm. 270(13), 1 de agosto de 2008. Universidad de Barcelona. Disponible en http://www.ub.es/geocrit/sn/ sn-270/sn-270-13.htm

BOTTOMS, A. (2007): «Place, space and disorder» en The Oxford handbook of criminology (Maguire, M., Morgan, R. y Reiner, R., Eds.). Oxford. Oxford UniversityPress, 528-574.

CASTELLS, M. (1995): La ciudad informacional. Tecnologías de la información, reestructuración económica y el proceso urbano-regional. Madrid. Alianza.

CECCATO, V. y OBERWITTLER, D. (2008): «Comparing spatial patterns of robbery: evidence from a Western and an Eastern European city» enCities, $\mathrm{n}^{\circ}$ 25, 185-196.

COHEN, L.E. y FELSON, M. (1979): «Social change and crime rate trends: a routine activities approach» en American Sociological Review, vol. 44, 1979, 588-608.

mayor grado de constitución cuando un mayor número de entradas desemboquen directamente en ella, y el grado será menor cuando éstas se encuentren separadas de la calle por verjas o setos, o por un espacio semipúblico o semiprivado. 
DEAR, M.J. y WOLCH, J.R. (1989): «How territory shapes social life» en The power of Geography. How territory shapes social life (Wolch, J.R. y Dear, M.J., Eds.). Boston. Unwin Hyman, 1989, 3-18.

DÍAZ, E.Ma(2005):«El megaproyecto urbano del sur metropolitano de Madrid: MadridXanadú y su entorno» en La ciudad y el miedo. VII Coloquio de Geografía Urbana (Gutiérrez, O., coord.). Girona. Universitat de Girona, 195-208.

DOMÍNGUEZ, J. L. y RODRÍGUEZ, A. (2003): «Lógica actuarial, seguridad y sistema de justicia penal» en La seguridad en la sociedad del riesgo (Agra, C. et al, Eds.). Barcelona, Atelier, 329-352.

FOUCAULT, M. (1981): Un diálogo sobre el poder. Madrid, Alianza/Materiales.

FRAILE, P., BONASTRA, Q. et al. (2010): Seguridad, temores y paisaje urbano. Barcelona, Ediciones del Serbal.

FRAILE, P., BONASTRA, Q. (2011): «Espacio, delincuencia y seguridad: hacia el diseño de un modelo de análisis espacial» en Boletin de la Asociación de Geógrafos Españoles, $\mathrm{n}^{\mathrm{o}} 57$, p. 123-146.

FRAILE, P.; BONASTRA, Q. et al. (2012): Delito, victimización y conflicto en la ciudad de Lleida (2008-2011). Lleida, Edicions y Publicacions de la Universitat de Lleida.

FRAILE, P.; BONASTRA, Q. et al. (2012): Delito, victimización y conflicto en la ciudad de Tarragona (2008-2011). Lleida, Edicions y Publicacions de la Universitat de Lleida.

FRAILE, P.; BONASTRA, Q. et al. (2012): Delito, victimización y conflicto en la ciudad de Girona (2008-2011). Lleida, Edicions y Publicacions de la Universitat de Lleida.

GIDDENS, A. (1999): Consecuencias de la modernidad. Madrid, Alianza.

GREGORY, D. y URRY, J. (Eds.) (1985): Social relations and spatial structures. London. Macmillan.

HEBBERECHT, P. (2003): «Sociedad de riesgos y política de seguridad» en La seguridad en la sociedad del riesgo. Un debate abierto (da AGRA, C. et al. Eds.). Barcelona. Atelier, 353-365.

HERNANDO, F. (2006): «Eclecticismo y diversidad en la Geografía del Crimen y la Delincuencia en el cambio de siglo» en Anales de Geografía de la Universidad Complutense, vol. 26, 9-30.

HERNANDO, F. (2001-2002): «Diferentes tipos de espacios delictivos en el municipio de Madrid» en Boletín de la Real Sociedad Geográfica, vols. CXXXVII-CXXXVIII, 203-215.

HERNANDO, F. (coord.) (2007a): Atlas de la Seguridad de Madrid. Madrid, Ayuntamiento de Madrid.

HERNANDO, F. (2007b): «Estudio de los barrios preexistentes y emergentes: la trama urbana y su relación con la seguridad. Consideraciones prácticas sobre el urbanismo y la inseguridad» en Ponencias del Congreso Internacional de Ciudades, Urbanismo y Seguridad. Madrid: Ayuntamiento de Madrid, 87-120. Disponible en http://www.munimadrid. es/UnidadWeb/Contenidos/Publicaciones/TemaEmergencias/PonenciasCongresoCiudades/Ficheros/Parte2.1.pdf

HERNADO, F. (2008): «La seguridad en las ciudades: el nuevo enfoque de la geoprevención» en Scripta Nova. Revista Electrónica de Geografía y Ciencias Sociales, vol. XII, núm. 270(14), 1 de agosto de 2008. Universidad de Barcelona. Disponible en http://www. ub.es/geocrit/sn/sn-270/sn-270-14.htm 
HILLIER, B. y HANSON, J. (1984): The social logic of space. Cambridge: Cambridge University Press.

HILLIER, B. y SHAHBAZ, O. (2005): «High resolution analysis of crime patterns in urban Street networks: an initial statistics sketch from an ongoing study of a London borough» en Proceedings, 5th International Space Syntax Symposium (van Nes, a., ed.). Delft: TUDelft, 2005, 451-478.

KUBACKY, K., SKINNER, H., PARFITT, S., MOSS, G. (2005): «Comparing nightclub customers' preferences in existing and emerging markets» en Hospitality Management, $\mathrm{n}^{\circ} 26,2007,957-973$.

LOBO, M.A., GUIMARÃES, L.H. (2013): «Distribuição espacial da criminalidade no Centro Histórico da cidade de Belém (Pará/Brasil)» en Scripta Nova. Revista Electrónica de Geografía y Ciencias Sociales, vol. XVII, núm. 456, 10 de noviembre de 2013. Universidad de Barcelona. Disponible en http://www.ub.edu/geocrit/sn/sn-456.htm

MAILLARD, J. (2002): Atlas Akal de la criminalidad financiera. Del narcotráfico al blanqueo de capitales. Madrid. Akal.

MANZO, J. (2005): «Social control and the management of «Personal» Space in Shipping Malls» en Space and Culture, vol. 8, $\mathrm{n}^{\circ}$ 83, 83-97.

MURO, J.I. (2012): «Les zones de la ciutatielsusos del sòlurbà» en Història de Tarragona (vol. 6). La ciutat actual. Geografia i Urbanisme (Saladié, O. et al.). Lleida, Pagès Editors, 217-276.

NADAL, J. (2003): «Vintanys del Pla Especial, un plaquirúrgic, no cosmètic» en Girona, 20 anys del Pla Especial del Barri Vell (1983-2003) (Birulés, J.M., coord.). Girona. Ajuntament de Girona, 43-68.

NELSON, A.L., BROMLEY, R.D.F. y THOMAS, C.J. (2001): «Identifying micro-spatial and temporal patterns of violent crime and disorder in the British city centre» en Applied Geography, vol. 21, 249-274.

NEWMAN, O. (1971): Defensible Space: People and design in the violent city. London. Architectural Press.

NEWMAN, O. (1996): Creating Defensible Space. Washington D. C., Department of Housing and Urban Development. Office of Policy Development and Research.

OLIVERAS, J. (2012): «Les activitats econòmiques» en Història de Tarragona (vol. 6). La ciutat actual. Geografia i Urbanisme (Saladié, O. et al.). Lleida, Pagès Editors, 109-150.

POYNER, B. y WEBB, B. (1986): «Reducing theft from Shopping baggs in city center markets» en Situational crime prevention: successful case studies, vol. 2 (Clarke, R.V., ed). Guilderland, NY. Harrow and Heston, 83-89.

RECASENS, A. (2003): «Globalización, riesgo y seguridad: el continuóse de lo que alguien empezóse» en La seguridad en la sociedad del riesgo (Agra C. et al, Eds.). Barcelona, Atelier, 365-379.

REICHMAN, N. (1986): «Managing crime risks: toward and insurance based model of social control» en Research in Law, Deviance and Social Control, $\mathrm{n}^{\circ}$ 8, 151-172.

RICHARDSON, A. y BUDD, T. (2003): Alcohol, crime and disorder: a study of young adults. Home Office Research Study 263. London. Home Office Research.

SAHBAZ, O y HILLIER, B. (2007): «The story of the crime: functional, temporal and spatial tendencies in street robbery» en Proceedings, $6^{\text {th }}$. International Space Syntax Symposium, Istambul 2007, 22/01-22/14. 
SHAW, C. y McKAY, H. (1942): Juvenile delinquency and urban áreas. Chicago. University of Chicago Press.

STANGELAND, P. (1995): The Crime Puzzle. Crime Patterns and Crime Displacement in Southern Spain. Málaga, Miguel Gómez Eds.

STANGELAND, P. y GARRIDO, M.J. (2004): El mapa del crimen. Herramientas geográficas para policías y criminólogos. Valencia, Tirant lo Blanc.

SUAU, P. y FONT, N. (2005): «¿Tienen calidad pública los centros comerciales? Un análisis del caso de Barcelona» en La ciudad y el miedo. VII Coloquio de Geografía Urbana (Gutiérrez, O., coord.). Girona. Universitat de Girona, 245-256.

TROITIÑO, M.A. (2003): «La protección, recuperación y revitalización funcional de los centros históricos» en Ciudades, arquitectura y espacio urbano (Capel, H., coord.). Almería. Caja Rural Intermediterránea, Colección Mediterráneo Económico n ${ }^{\circ} 3,131-160$.

VILAGRASA, J., BRU, J., MARTÍ, J. y BARRUFET, A. (1996): «Característiques socioeconòmiques i estructura física del centre històric de Lleida» en Treballs de la Societat Catalana de Geografia, vol. XI, n 41, 323-378.

VOZMEDIANO, L., SAN JUAN, C. (2010): Criminología ambiental. Ecología del delito y de la seguridad. Barcelona. UOC.

WOLCH, J.R; DEAR, M.J. (Eds.) (1989): The power of Geography. How territory shapes social life. Boston. Unwin Hyman. 